\title{
Investigation of Molecular Interactions in the Carboxylato Zn(II) and Cd(II) Macrocyclic Complexes
}

\author{
Jin Suk Kwag, Mi Hyang Jeong, Alan J. Lough, ${ }^{\dagger}$ and Ju Chang Kim* \\ Department of Chemistry, Pukyong National University, Busan 608-737, Korea. *E-mail: kimjc@pknu.ac.kr \\ ${ }^{\dagger}$ Department of Chemistry, University of Toronto, Toronto, ONT, Canada M5S $3 H 6$ \\ Received May 9, 2010, Accepted May 24, 2010
}

Key Words: Zinc(II) complex, Cadmium(II) complex, Crystal structure, Coordination polymer

Coordination polymers on the basis of the assembly of metal ion "connectors" and multidentate ligand "linkers" have been of great interest due to their intriguing architectures and versatile applications. ${ }^{1-9}$ Metallotetraazamacrocycles bearing equatorial amines coordinated to the central metal ions and axial sites opened for incoming "linkers" are good "connectors" as building blocks for the construction of coordination polymers. ${ }^{10-15}$ Among multidentate ligands, polycarboxylates have been widely used as "linkers" due to their versatile coordination modes toward metal ions. ${ }^{16-19}$ An fdc ( $\mathrm{fdc}=1,1$ '-ferrocenedicarboxylate ion) ligand as a kind of polycarboxylates has attracted attention not only in the field of coordination chemistry but also in the field of organometallic chemistry. ${ }^{20-23}$ During our efforts to explore the molecular interactions between metallomacrocycles and polycarboxylate ligands in zinc(II) and cadmium(II) tetraazamacrocycles containing bridging polycarboxylate ligands, we successfully synthesized and structurally characterized two 1D zinc(II) coordination polymers $\mathbf{1}$ and $\mathbf{2}$, where each ferrocenyl of bridging fdc ligands adopts different conformation, and a macrocyclic cadmium(II) dimer 3 . Thus, two $\mathrm{Cp}(\mathrm{Cp}=$ cyclopentadienyl) rings of fdc ligands in $\mathbf{1}$ are mutually staggered, whereas they are eclipsed in $\mathbf{2}$. The cadmium(II) cyclams with folded macrocycles are bridged by an oxalate ligand in $\mathbf{3}$. In this report we describe the details of the synthesis and structures of 1-3.

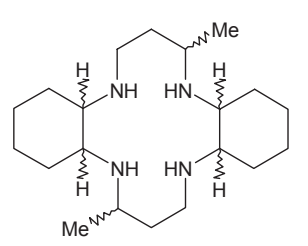

$\mathbf{L}$

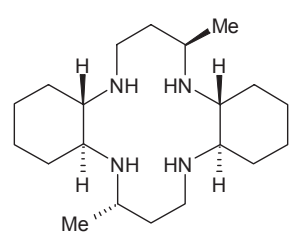

L2

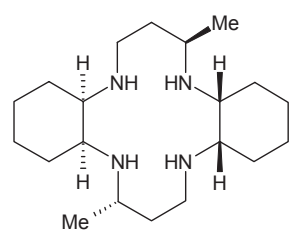

L1

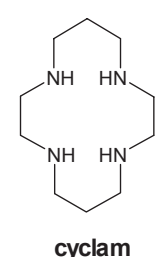

cyclam

\section{Experimental Section}

Materials, methods and apparatus. All chemicals used in the synthesis were of reagent grade and used without further purification. Distilled water was used for all procedures. Infrared spectra of solid samples were recorded on a Perkin-Elmer Paragon 1000 FT-IR spectrophotometer between $4000 \mathrm{~cm}^{-1}$ and $400 \mathrm{~cm}^{-1}$ as Nujol mulls on $\mathrm{KBr}$ discs. UV-vis spectra were measured on a Cary $1 \mathrm{C}$ spectrophotometer within the range $200-800 \mathrm{~nm}$. Elemental and thermal analyses were performed by the Korea Research Institute of Chemical Technology, Daejeon, Korea. The free ligands $\mathbf{L} \mathbf{1}$ and $\mathbf{L} 2$ were synthesized by literature procedures. ${ }^{24}$ The precursor complex $\mathrm{Zn}(\mathbf{L 1})\left(\mathrm{NO}_{3}\right)_{2}$ or $\mathrm{Zn}(\mathbf{L} \mathbf{2})\left(\mathrm{NO}_{3}\right)_{2}$ was prepared by refluxing ligand $\mathbf{L 1}$ or $\mathbf{L 2}$ (336 mg, 1.0 mmole) and $\mathrm{Zn}\left(\mathrm{NO}_{3}\right)_{2} \cdot 6 \mathrm{H}_{2} \mathrm{O}$ (300 mg, 1.01 mmole) in stirring methanol for a day, filtering the white powder, washing with methanol, and finally drying in air. Yield $>95 \%$. The starting $\mathrm{Cd}($ cyclam $)\left(\mathrm{ClO}_{4}\right)_{2}$ complex was prepared by reported methods. ${ }^{25}$

Caution! The perchlorate salts used in this study are potentially explosive and should be handled in small quantities.

Synthesis of 1: Compound 1 was prepared by adding an aqueous solution of sodium fdc ( $32 \mathrm{mg}, 0.1 \mathrm{mmole})$ to a DMF solution of $\mathrm{Zn}(\mathbf{L 1})\left(\mathrm{NO}_{3}\right)_{2}$ (53 mg, $\left.0.1 \mathrm{mmole}\right)$. Slow evaporation of the solution provided orange single crystals of $\mathbf{1}$. Suitable crystals 1 for X-ray diffraction studies and other measurements were manually collected under a microscope. Yield $>90 \%$. Anal. Calcd. for $\mathrm{C}_{32} \mathrm{H}_{54} \mathrm{FeN}_{4} \mathrm{O}_{7} \mathrm{Zn}(\mathbf{1})$ : C, 52.79\%; H, 7.48\%; N, 7.70\%. Found C, 52.72\%; H, 7.29\%; N, 7.70\%.

Synthesis of 2: Compound 2 was prepared by a same method described for 1 using $\mathrm{Zn}(\mathbf{L} 2)\left(\mathrm{NO}_{3}\right)_{2}$ instead of $\mathrm{Zn}(\mathbf{L} \mathbf{1})\left(\mathrm{NO}_{3}\right)_{2}$. Yield $>90 \%$. Anal. Calcd. for $\mathrm{C}_{32} \mathrm{H}_{52} \mathrm{FeN}_{4} \mathrm{O}_{6} \mathrm{Zn}(2)$ : C, 54.13\%; H, 7.38\%; N, 7.89\%. Found C, 54.03\%; H, 7.26\%; N, 7.87\%.

Synthesis of 3: To an aqueous solution of $\mathrm{Cd}($ cyclam $)\left(\mathrm{ClO}_{4}\right)_{2}$ (511 mg, 1.0 mmole) was added an aqueous solution of $\mathrm{K}_{2}$ oxalate $\cdot \mathrm{H}_{2} \mathrm{O}$ (92 mg, $\left.0.5 \mathrm{mmole}\right)$. The mixture was allowed in an open beaker at room temperature. Colorless plates of $\mathbf{3}$ were obtained in a week. Suitable crystals of $\mathbf{3}$ for X-ray diffraction studies and other measurements were manually collected under a microscope. Yield $>90 \%$. Anal. Calcd. for $\mathrm{C}_{22} \mathrm{H}_{48} \mathrm{~N}_{8} \mathrm{Cd}_{2} \mathrm{Cl}_{2}$ $\mathrm{O}_{12}$ : C, 28.93\%; H, 5.26\%; N, 12.28\%; O, 21.04\%. Found C, $29.20 \%$; H, 5.24\%; N, $12.20 \%$; O, 21.22\%.

X-ray crystallography. A summary of selected crystallographic data and structure refinement for $\mathbf{1 - 3}$ is given in Table 1. $X$-ray data were collected on a Nonius Kappa CCD diffractometer, using graphite monochromated Mo K $\alpha$ radiation $(\lambda=$ $0.71073 \AA$ ). A combination of $1^{\circ} \phi$ and $\omega$ (with $\kappa$ offsets) scans were used to collect sufficient data. The data frames were integrated and scaled using the Denzo-SMN package. ${ }^{26}$ The structure was solved and refined using the SHELXTL\PC V6.1 package. $^{27}$ 
Table 1. Crystal data and structure refinement for 1-3

\begin{tabular}{|c|c|c|c|}
\hline & 1 & 2 & 3 \\
\hline Empirical formula & $\mathrm{C}_{32} \mathrm{H}_{54} \mathrm{FeN}_{4} \mathrm{O}_{7} \mathrm{Zn}$ & $\mathrm{C}_{32} \mathrm{H}_{52} \mathrm{FeN}_{4} \mathrm{O}_{6} \mathrm{Zn}$ & $\mathrm{C}_{22} \mathrm{H}_{48} \mathrm{~N}_{8} \mathrm{Cd}_{2} \mathrm{Cl}_{2} \mathrm{O}_{12}$ \\
\hline Formula weight & 728.01 & 710.00 & 912.38 \\
\hline Temperature (K) & $150(1)$ & $150(1)$ & $150(2)$ \\
\hline Wavelength & $0.71073 \AA$ & $0.71073 \AA$ & $0.71073 \AA$ \\
\hline Crystal system & Triclinic & Monoclinic & Triclinic \\
\hline Space group & $P_{\overline{1}}$ & $C 2 / c$ & $P \overline{1}$ \\
\hline \multirow[t]{6}{*}{ Unit cell dimensions } & $a=9.9439(3) \AA$ & $a=17.5564(5) \AA$ & $\mathrm{a}=8.1346(3) \AA$ \\
\hline & $\mathrm{b}=12.2581(3) \AA$ & $\mathrm{b}=10.2621(3) \AA$ & $\mathrm{b}=12.0765(4) \AA$ \\
\hline & $c=15.7746(5) \AA$ & $\mathrm{c}=18.3590(5) \AA$ & $\mathrm{c}=17.2460(9) \AA$ \\
\hline & $\alpha=111.4410(16)^{\circ}$ & & $\alpha=85.184(3)^{\circ}$ \\
\hline & $\beta=90.2750(16)^{\circ}$ & $\beta=102.2230(16)^{\circ}$ & $\beta=84.483(2)^{\circ}$ \\
\hline & $\gamma=111.2840(18)^{\circ}$ & & $\gamma=85.437(2)^{\circ}$ \\
\hline Volume & $1646.59(8) \AA^{3}$ & $3232.68(16) \AA^{3}$ & $1676.03(12) \AA^{3}$ \\
\hline $\mathrm{Z}$ & 2 & 4 & 2 \\
\hline Density (calcd) & $1.468 \mathrm{Mg} / \mathrm{m}^{3}$ & $1.459 \mathrm{Mg} / \mathrm{m}^{3}$ & $1.808 \mathrm{Mg} / \mathrm{m}^{3}$ \\
\hline Absorption coefficient & $1.222 \mathrm{~mm}^{-1}$ & $1.240 \mathrm{~mm}^{-1}$ & $1.497 \mathrm{~mm}^{-1}$ \\
\hline Independent reflections & $7481[\mathrm{R}(\mathrm{int})=0.0425]$ & $3408[\mathrm{R}(\mathrm{int})=0.0660]$ & $7601[\mathrm{R}(\mathrm{int})=0.0534]$ \\
\hline Goodness-of-fit on $F^{2}$ & 1.036 & 1.059 & 1.058 \\
\hline Final $R$ indices $[I>2 \sigma(I)]$ & $R_{1}=0.0425, w R_{2}=0.1007$ & $R_{1}=0.0469, w R_{2}=0.1115$ & $R_{1}=0.0558, w R_{2}=0.1302$ \\
\hline $\mathrm{R}$ indices (all data) & $R_{1}=0.0655, w R_{2}=0.1135$ & $R_{1}=0.0706, w R_{2}=0.1303$ & $R_{1}=0.0933, w R_{2}=0.1533$ \\
\hline
\end{tabular}
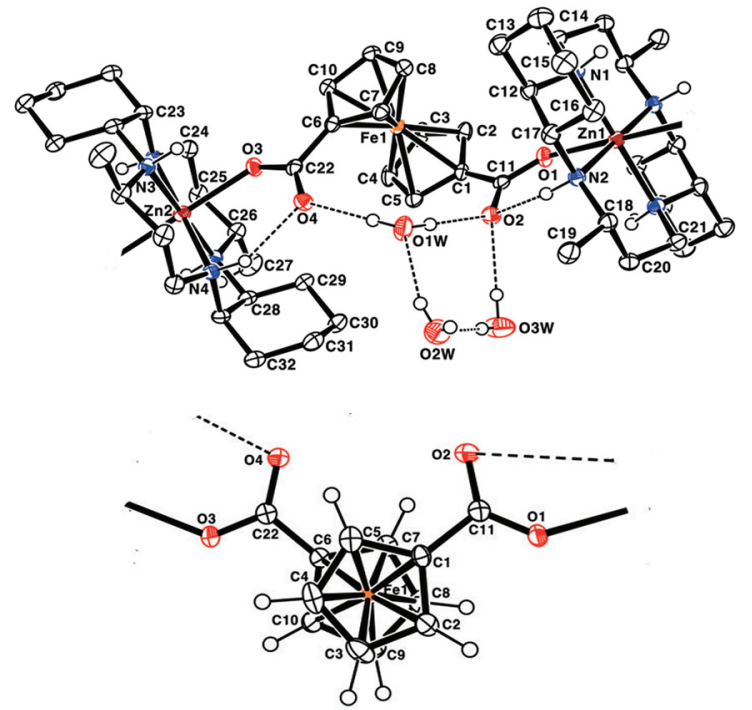

Figure 1. Molecular structure of $\mathbf{1}$ with atom-labeling scheme (top) and two Cp rings showing staggered (bottom). Hydrogen atoms other than those participating in hydrogen bonding and on the $\mathrm{Cp}$ rings are omitted for clarity. Selected bond distances $(\AA)$ and angles $\left({ }^{\circ}\right)$ : Zn1-N1, 2.1008(19); Zn1-N2, 2.110(2); Zn2-N3, 2.150(2); Zn2-N4, 2.082(2); Zn1-O1, 2.2107(16); Zn2-O3, 2.2042(17); N1-Zn1-N2, 84.41(8); N1-Zn1-N2\#1, 95.59(8); N1-Zn1-O1\#1, 88.36(7); N2-Zn1-O1\#1, 89.16(7); N1-Zn1-O1, 91.64(7); N2-Zn1-O1, 90.84(7). Symmetry transformations used to generate equivalent atoms: \#1-x,-y+1,-z.

Refinement was performed by full-matrix least squares on $F^{2}$ using all data (negative intensities included). Hydrogen atoms were included in calculated positions.

\section{Results and Discussion}

The different ferrocenyl conformations of bridging fdc ligands in $\mathbf{1}$ and $\mathbf{2}$ can be induced by the introduction of macrocycles $\mathbf{L 1}$ and $\mathbf{L 2}$. The macrocycles $\mathbf{L 1}$ and $\mathbf{L} \mathbf{2}$ are diastereomerically related each other in which the macrocycle $\mathbf{L} \mathbf{1}$ contains two cis-fused cyclohexane rings on a cyclam and the macrocycle L2 contains two trans-fused cyclohexane rings on a cyclam. ${ }^{24}$ The solid state structures of $\mathbf{1}$ and $\mathbf{2}$ were determined by X-ray diffraction methods. An ORTEP drawing of the complex $\mathbf{1}$ is shown in Figure 1. The structure of $\mathbf{1}$ exhibits a 1D coordination polymer with the basic unit of $[\mathrm{Zn}(\mathbf{L 1})(\mathrm{fdc})]$ which is composed of two independent macrocycles and bridging fdc ligands. Each zinc atom sits on an inversion center and two $\mathrm{Cp}$ rings of fdc ligands are staggered. The staggered conformation of two Cp rings in $\mathbf{1}$ is induced by the introduction of macrocycle $\mathbf{L 1}$ which has larger steric hindrance compared to that of the macrocycle $\mathbf{L} \mathbf{2}$ as well as hydrogen bonds between fdc ligands and three lattice water molecules. In 2D sheets, these hydrogen bonds pull the neighboring $1 \mathrm{D}$ polymeric chain closer, resulting in a larger steric hindrance between the $\mathrm{Cp}$ rings of $1 \mathrm{D}$ interchains. The average Fe-C bond distance of Cp is $2.052 \AA$ and the Fe-Cp (centroid) distance is $1.656 \AA$ in a staggered ferrocenyl moiety. These are comparative to those reported for related ferrocene compounds. ${ }^{28,29}$ The rotational angle between the two $\mathrm{Cp}$ rings in $\mathbf{1}$ is close to $46.7^{\circ}$ (measured by $\mathrm{C}(11)-\mathrm{Cp}$ (centroid)-Cp (centroid)-C(8)). Another pertinent structural feature found in $\mathbf{1}$ is that each 1D chain is linked together via hydrogen bonds. Water molecules mediate in connecting each 1D chain (Figure 2, Table 2). Through these hydrogen bonding interactions, the complex 1 extends its structure to form a 2D supramolecule. The complex $\mathbf{2}$ containing the macrocycle $\mathbf{L} \mathbf{2}$ exhibits a $1 \mathrm{D}$ coordination polymer with a basic $[\mathrm{Zn}(\mathbf{L 2})(\mathrm{fdc})]$ unit (Figure 3). Similarly to $\mathbf{1}$, each zinc atom sits on an inversion center. However, in the complex 2 , two $\mathrm{Cp}$ rings of bridging fdc ligands are an eclipsed conformation (Figure 3 ). The complex $\mathbf{2}$ with $\mathbf{L} \mathbf{2}$ which has a smaller steric hindrance compared 
Table 2. Hydrogen bonds for $\mathbf{1}\left(\AA\right.$ and $\left.{ }^{\circ}\right)$

\begin{tabular}{|c|c|c|c|c|}
\hline $\mathrm{D}-\mathrm{H} \cdots \mathrm{A}$ & $d(D-H)$ & $\mathrm{d}(\mathrm{H} \cdots \mathrm{A})$ & $d(D \cdots A)$ & $<(\mathrm{DHA})$ \\
\hline $\mathrm{N} 2-\mathrm{H} 2 \cdots \mathrm{O} 2 \# 1$ & 0.93 & 2.08 & $2.967(3)$ & 159.4 \\
\hline $\mathrm{N} 4-\mathrm{H} 4 \cdots \mathrm{O} 4$ & 0.93 & 2.12 & $2.967(3)$ & 150.9 \\
\hline $\mathrm{O} 1 \mathrm{~W}-\mathrm{H} 1 \mathrm{WA} \cdots \mathrm{O} 2$ & 0.84 & 1.96 & $2.804(3)$ & 179.4 \\
\hline O1W-H1WB $\cdots \mathrm{O} 4$ & 0.84 & 1.96 & $2.800(2)$ & 179.4 \\
\hline $\mathrm{O} 2 \mathrm{~W}-\mathrm{H} 2 \mathrm{WA} \cdots \mathrm{O} 1 \mathrm{~W}$ & 0.84 & 2.06 & $2.879(3)$ & 163.3 \\
\hline $\mathrm{O} 2 \mathrm{~W}-\mathrm{H} 2 \mathrm{WB} \cdots \mathrm{O} 1 \mathrm{~W} \# 3$ & 0.84 & 2.16 & $2.990(3)$ & 167.6 \\
\hline $\mathrm{O} 3 \mathrm{~W}-\mathrm{H} 3 \mathrm{WA} \cdots \mathrm{O} 2$ & 0.84 & 2.07 & $2.907(3)$ & 179.6 \\
\hline $\mathrm{O} 3 \mathrm{~W}-\mathrm{H} 3 \mathrm{WB} \cdots \mathrm{O} 2 \mathrm{~W}$ & 0.84 & 2.10 & $2.936(3)$ & 179.6 \\
\hline
\end{tabular}

Symmetry transformations used to generate equivalent atoms: $\# 1-\mathrm{x},-\mathrm{y}+1,-\mathrm{z}$ $\# 2-x+1,-y+3,-z+1 \# 3-x+1,-y+2,-z$.

Table 3. Hydrogen bonds for $2\left(\AA\right.$ and $\left.^{\circ}\right)$

\begin{tabular}{lllll}
\hline $\mathrm{D}-\mathrm{H} \cdots \mathrm{A}$ & $\mathrm{d}(\mathrm{D}-\mathrm{H})$ & $\mathrm{d}(\mathrm{H} \cdots \mathrm{A})$ & $\mathrm{d}(\mathrm{D} \cdots \mathrm{A})$ & $<(\mathrm{DHA})$ \\
\hline $\mathrm{N} 2-\mathrm{H} 2 \cdots \mathrm{O} 2 \# 2$ & 0.93 & 2.13 & $2.957(3)$ & 146.9 \\
O1W-H3WA $\cdots \mathrm{O} 2$ & 0.78 & 2.08 & $2.823(3)$ & 158.7 \\
O1W-H3WB $\cdots \mathrm{O} 2 \# 3$ & 0.85 & 2.07 & $2.861(3)$ & 154.0
\end{tabular}

Symmetry transformations used to generate equivalent atoms: $\# 1-\mathrm{x}+1, \mathrm{y}$, $-z+3 / 2 \# 2-x+1,-y+1,-z+1 \# 3-x+1,-y,-z+1$.
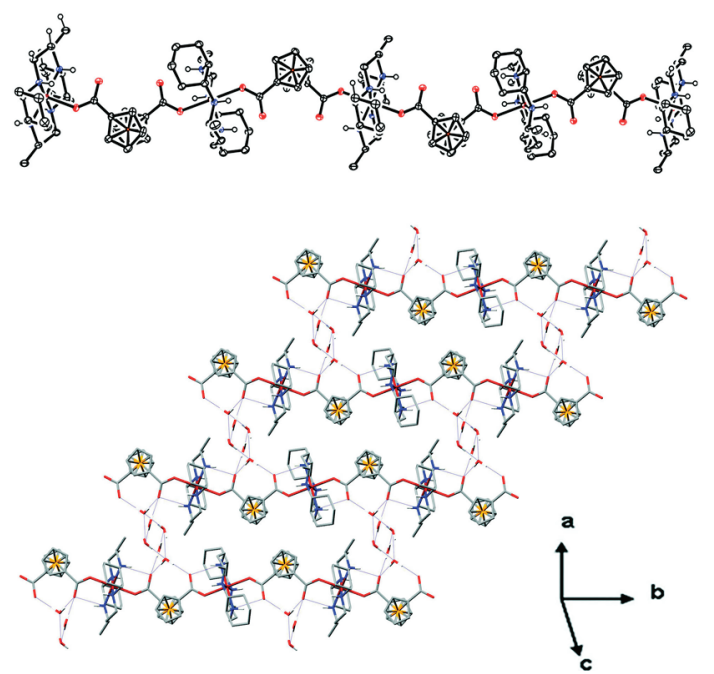

Figure 2. Extended molecular structure of 1 illustrating a 1D coordination polymer (top) and 2D supramolecule (bottom).

to that of the macrocycle $\mathbf{L} 1$ exhibits symmetric hydrogen bonds with two water molecules. In 2D sheets, the ferrocenyl groups in one polymeric chain reside far apart from another ferrocenyl groups of neighboring polymeric chain due to these symmetric hydrogen bonds, resulting in a smaller steric hindrance between the $\mathrm{Cp}$ rings of $1 \mathrm{D}$ interchains (Figure 4 ). Under these circumstances, the complex 2 favorably adopts the eclipsed conformation of two $\mathrm{Cp}$ rings of bridging fdc ligands. The complex 2 shows the average $\mathrm{Fe}-\mathrm{C}$ of $\mathrm{Cp}$ distance of $2.045 \AA$ and $\mathrm{Fe}-\mathrm{Cp}$ (centroid) distance of $1.647 \AA$. These are also similar to those found in the complex 1 and other related ferrocene complexes. $^{28,29}$ The rotational angle between the two Cp rings in $\mathbf{1}$ is close to $7.2^{\circ}$ (measured by C(6)-Cp (centroid)-Cp (centroid)$\mathrm{C}(3) \# 1$; symmetry code: \#1-x+1,y,-z+3/2). Water molecules in $\mathbf{2}$ interact with each other as well as carboxylates of $\mathrm{Cp}$ rings
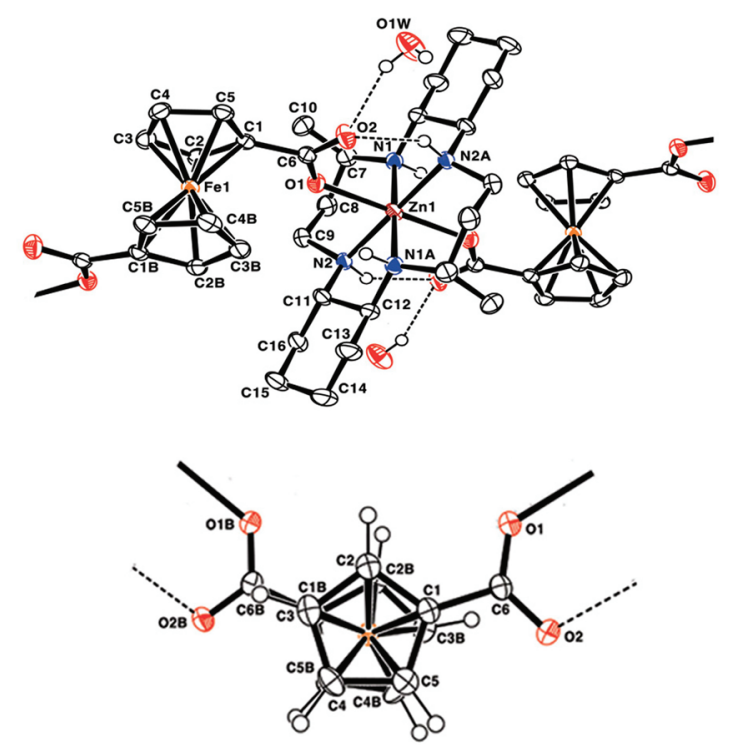

Figure 3. Molecular structure of $\mathbf{2}$ with atom-labeling scheme (top) and two $\mathrm{Cp}$ rings showing eclipsed (bottom). Hydrogen atoms other than those participating in hydrogen bonding and on the Cp rings are omitted for clarity. Selected bond distances $(\AA)$ and angles ( $\left(^{\circ}\right)$ : Zn(1)$\mathrm{N}(1), 2.129(2) ; \mathrm{Zn}(1)-\mathrm{N}(2), 2.083(2) ; \mathrm{Zn}(1)-\mathrm{O}(1), 2.204(2)$; N1-Zn1N2, 95.35(9); N1-Zn1-N2\#2, 84.65(9); N1-Zn1-O1\#2, 85.39(9); N2Zn1-O1\#2, 94.33(9); N1-Zn1-O1, 94.61(9); N2-Zn1-O1, 85.67(9). Symmetry transformations used to generate equivalent atoms: \#2 $-\mathrm{x}+1,-\mathrm{y}+1,-\mathrm{z}+1$.

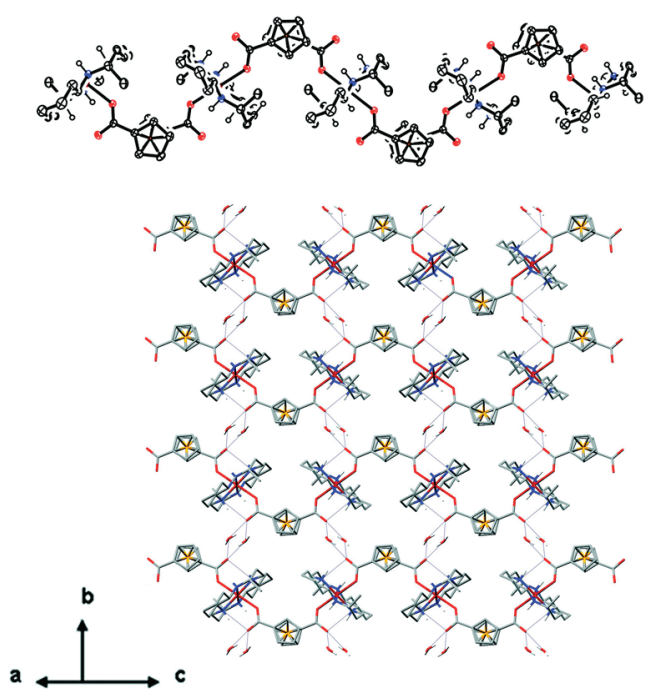

Figure 4. Extended molecular structure of 2 illustrating a 1D coordination polymer (top) and 2D supramolecule (bottom).

to form a 2D supramolecule (Figure 4, Table 3). The results in $\mathbf{1}$ and $\mathbf{2}$ are in contrast to the previous reports that two Cp rings of a ferrocene nearly adopt an eclipsed conformation $\left(D_{5 h}\right)$ in the gas phase, ${ }^{30,31}$ meanwhile, staggered $\mathrm{Cp}$ rings of a ferrocene $\left(D_{5 d}\right)$ are in single crystals. ${ }^{31,32}$

The structure for 3 contains two independent centrosymmetric dimers. One of these along with the anions is shown in Figure 5. The basic structure of $\mathbf{3}$ exhibits a macrocyclic cadmium(II) dimer, where each cyclam is folded in a cis-I $(R, S, R, S)$ fashion and an oxalate ligand acts as a bridge in a bis-biden- 


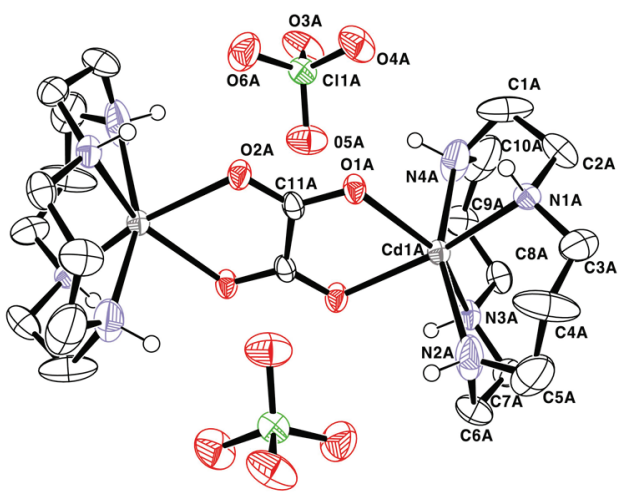

Figure 5. Molecular structure of $\mathbf{3}$ with atom-labeling scheme. Hydrogen atoms other than those on the nitrogen atoms are omitted for clarity. Selected bond distances $(\AA)$ and angles $\left({ }^{\circ}\right)$ : Cd1A-N1A, 2.340(5); Cd1A-N2A, 2.348(7); Cd1A-N3A, 2.333(5); Cd1A-N4A, 2.328(6); Cd1A-O1A, 2.292(4); Cd1A-O2A\#1, 2.312(4); O1A-Cd1AO2A\#1, 72.29(14); O1A-Cd1A-N4A, 87.1(2); O2A\#1-Cd1A-N4A, 107.9(2); O1A-Cd1A-N3A, 148.83(16); O2A\#1-Cd1A-N3A, 80.42 (16); N4A-Cd1A-N3A, 87.2(3); O1A-Cd1A-N1A, 90.64(16); O2A\#1Cd1A-N1A, 159.94(18); N4A-Cd1A-N1A, 81.0(2); N3A-Cd1A-N1A, 118.61(17); O1A-Cd1A-N2A, 114.9(2); O2A\#1-Cd1A-N2A, 89.3 (2); N4A-Cd1A-N2A, 155.8(2); N3A-Cd1A-N2A, 78.8(3); N1ACd1A-N2A, 88.5(2). Symmetry transformations used to generate equivalent atoms: $\# 1-\mathrm{x}+1,-\mathrm{y}+1,-\mathrm{z}$.

tate mode. Although folded cyclams in several metallocyclams are commonly observed, the crystal structure of an unsubstituted cadmium(II) cyclam complex with a cis-I configuration is extremely rare. As far as we are aware, only one such an example has been reported earlier. ${ }^{25}$

The infrared spectra of $\mathbf{1}$ and $\mathbf{2}$ showed strong absorptions at $1639,1555 \mathrm{~cm}^{-1}$ (1) and 1641, $1555 \mathrm{~cm}^{-1}$ (2) (vCOO) due to the carboxylate groups of fdc ligands. In addition, bands at $3390 \mathrm{~cm}^{-1}$ (1) and $3433 \mathrm{~cm}^{-1}(2)(\mathrm{vOH})$ were observed, indicating the presence of lattice water molecules. The bands at $3295,3138 \mathrm{~cm}^{-1}$ (1) and $3263,3171 \mathrm{~cm}^{-1}$ (2) were assignable to $v \mathrm{NH}$ from the macrocycles. The infrared spectrum of $\mathbf{3}$ showed a single intense $v \mathrm{NH}$ stretching vibration at $3293 \mathrm{~cm}^{-1}$ and a strong absorption at $1091 \mathrm{~cm}^{-1}$ due to $\mathrm{ClO}_{4}{ }^{-}$ions. TGA curves for 1 showed a first weight loss of 7.3\% (calculated 7.4\%) over $80-140{ }^{\circ} \mathrm{C}$ corresponding to the loss of three water molecules. On further heating, the $\mathrm{ZnO}$ and $\mathrm{Fe}_{2} \mathrm{O}_{3}$ residues (observed $32.6 \%$ calculated $33.1 \%$ ) were remained above $450{ }^{\circ} \mathrm{C}$. TGA curves for 2 showed a first weight loss of 5.9\% (calculated $5.1 \%$ ) over $80-210{ }^{\circ} \mathrm{C}$ corresponding to the loss of two water molecules. Final residues (observed $22.0 \%$ calculated $21.6 \%$ ) were remained with the $\mathrm{ZnO}$ and $\mathrm{FeO}$ composition. The electronic spectra of $\mathbf{1}$ and $\mathbf{2}$ in methanol exhibited bands at $447 \mathrm{~nm}$ for 1 and $445 \mathrm{~nm}$ for $\mathbf{2}$ which were typical for ferrocene complexes. ${ }^{33}$

In summary, we have prepared and fully characterized two zinc(II) macrocyclic complexes containing bridging fdc ligands, and a dimeric cadmium(II) cyclam bridged by an oxalate ligand. Although complexes $\mathbf{1}$ and $\mathbf{2}$ showed similar 1D coordination polymers, their ferrocenyl conformations are different, where two $\mathrm{Cp}$ rings of fdc ligands are staggered (in 1) and eclipsed (in 2). It is believed that the introduction of diastereomerically related macrocycles $\mathbf{L} \mathbf{1}$ and $\mathbf{L} \mathbf{2}$ causes different ferrocenyl conformations in complexes $\mathbf{1}$ and $\mathbf{2}$. The complex $\mathbf{3}$ has an unusual
cis-I configuration in the macrocyclic skeleton.

Supplementary Material. Crystallographic data have been deposited at the Cambridge Crystallographic Data Center (CCDC), CCDC Nos. 743179 (1), 743180 (2) and 775617 (3).

Acknowledgments. This work was supported by the Pukyong National University Research Fund in 2009 (PK-2009-22).

\section{References}

1. Kitagawa, S.; Kitaura, R.; Noro, S.-i. Angew. Chem. Int. Ed. 2004, 43, 2334.

2. Kumar, D. K.; Das, A.; Dastidar, P. Cryst. Growth \& Des. 2006, 6, 1903

3. Shyu, E.; Supkowski, R. M.; LaDuca, R. L. Cryst. Growth \& Des. 2009, 9, 2481.

4. He, J.; Yu, J.; Zhang, Y.; Pan, Q.; Xu, R. Inorg. Chem. 2005, 44, 9279.

5. Pan, L.; Olson, D. H.; Ciemnolonski, L. R.; Heddy, R.; Li, J. Angew. Chem. Int. Ed. 2006, 45, 616.

6. Dincă, M.; Yu, A. F.; Long, J. R. J. Am. Chem. Soc. 2006, 128, 8904.

7. Fang, Q.-R.; Zhu, G.-S.; Xue, M. X.; Sun, J.-Y.; Qiu, S.-L. Dalton Trans. 2006, 2399.

8. Han, H.; Zhang, S.; Hou, H.; Fan, Y.; Zhu, Y. Eur. J. Inorg. Chem. 2006, 1594.

9. Wang, L.; Yang, M.; Li, G.; Shi, Z.; Feng, S. Inorg. Chem. 2006, 45,2474

10. Lee, E. Y.; Suh, M. P. Angew. Chem. Int. Ed. 2004, 43, 2798.

11. Choi, H. J.; Suh, M. P. J. Am. Chem. Soc. 1998, 120, 10622.

12. Suh, M. P.; Shim, B. Y.; Yoon, T.-S. Inorg. Chem. 1994, 33, 5509.

13. Choi, H. J.; Suh, M. P. Inorg. Chem. 1999, 38, 6309.

14. Kim, J. A.; Park, H.; Kim, J. C.; Lough, A. J.; Pyun, S. Y.; Roh, J.; Lee, B. M. Inorg. Chim. Acta 2008, 361, 2087.

15. Park, H.; Kim, J. C.; Lough, A. J.; Lee, B. M. Inorg. Chem. Commun. 2007, 10, 303.

16. Kim, J. C.; Lough, A. J.; Kim, H. Inorg. Chem. Commun. 2002 , 5,771 .

17. Kim, J. C.; Jo, H.; Lough, A. J.; Cho, J.; Lee, U.; Pyun, S. Y. Inorg. Chem. Commun. 2003, 6, 474.

18. Kim, J. C.; Cho, J.; Lough, A. J. Inorg. Chim. Acta 2001, 317, 252.

19. Cho, J.; Lough, A. J.; Kim, J. C. Inorg. Chim. Acta 2003, 342, 305.

20. Meng, X.; Hou, H.; Li, G.; Ye, B.; Ge, T.; Fan, Y.; Zhu, Y.; Sakiyama, H. J. Organomet. Chem. 2004, 689, 1218.

21. Meng, X.; Li, G.; Hou, H.; Han, H.; Fan, Y.; Zhu, Y.; Du, C. J. Organomet. Chem. 2003, 679, 153.

22. Zevaco, T. A.; Görls, H.; Dinjus, E. Polyhedron 1998, 17, 613.

23. Yang, H.; Hou, H.; Fan, Y. Inorg. Chim. Acta 2009, 362, 2418.

24. Kang, S.-G.; Kweon, J. K.; Jeong, S.-K. Bull. Korean Chem. Soc. 1991, 12, 483.

25. Liang, X.; Parkinson, J. A.; Parsons, S.; Weishäupl, M.; Sadler, P. J. Inorg. Chem. 2002, 41, 4539.

26. Otwinowski, Z.; Minor, W. In Methods in Enzymology, Macromolecular Crystallography, Part A; Carter, C. W., Sweet, R. M., Eds.; Academic Press: London, 1997; pp 307-326.

27. Sheldrick, G. M. SHELXTL $\backslash P C$ V6.1, Bruker Analytical X-ray Systems, Madison, WI, 2001.

28. Ossola, F.; Tomasin, P.; Benetollo, F.; Foresti, E.; Vigato, P. A. Inorg. Chim. Acta 2003, 353, 292.

29. Cervantes-Lee, F.; Sharma, H. K.; Pannell, K. H.; DerecskeiKovacs, A.; Marynick, D. S. Organometallics 1998, 17, 3701.

30. Haaland, A. Acc. Chem. Res. 1979, 12, 415.

31. Mayor-López, M. J.; Weber, J.; Mannfors, B.; Cunningham, A. F. Jr. Organometallics 1998, 17, 4983.

32. Dunitz, J. D.; Orgel, L. E.; Rich, A. Acta Crystallogr. 1956, 9, 373.

33. Okada, Y.; Nakagawa, T.; Hayashi, T. Inorg. Chim. Acta 2001, $312,197$. 